\title{
Synthesis and Physicochemical Properties of Poly(vinyl) Alcohol Nanocomposites Reinforced with Nanocrystalline Cellulose from Tea (Camellia sinensis) Waste
}

\author{
Fauzi Handoko (D) and Yusril Yusuf *(D) \\ Department of Physics, Faculty of Mathematics and Natural Sciences, Universitas Gadjah Mada, \\ Yogyakarta 55281, Indonesia; fauzihandoko@mail.ugm.ac.id \\ * Correspondence: yusril@ugm.ac.id; Tel.: +62-812-275-970-07
}

check for

updates

Citation: Handoko, F.; Yusuf, Y. Synthesis and Physicochemical Properties of Poly(vinyl) Alcohol Nanocomposites Reinforced with Nanocrystalline Cellulose from Tea (Camellia sinensis) Waste. Materials 2021, 14, 7154. https://doi.org/ $10.3390 / \mathrm{ma} 14237154$

Academic Editors: Sławomir Borysiak and Izabela Ratajczak

Received: 10 September 2021 Accepted: 20 November 2021 Published: 24 November 2021

Publisher's Note: MDPI stays neutral with regard to jurisdictional claims in published maps and institutional affiliations.

Copyright: (c) 2021 by the authors. Licensee MDPI, Basel, Switzerland. This article is an open access article distributed under the terms and conditions of the Creative Commons Attribution (CC BY) license (https:// creativecommons.org/licenses/by/ $4.0 /)$.

\begin{abstract}
The purpose of this study was to utilize cellulose from tea waste as nanocrystalline cellulose (NCC), which is used as a filler in poly(vinyl) alcohol (PVA) nanocomposites. To obtain the NCC, a chemical process was conducted in the form of alkali treatment, followed by bleaching and hydrolysis. Nanocomposites were formed by mixing PVA with various NCC suspensions. With chemical treatment, lignin and hemicellulose can be removed from the tea waste to obtain NCC. This can be seen in the functional groups of cellulose and the increase in crystallinity. The NCC had a mean diameter of $6.99 \pm 0.50 \mathrm{~nm}$. Furthermore, the addition of NCC to the PVA nanocomposite influenced the properties of the nanocomposites. This can be seen in the general increase in opacity value, thermal and mechanical properties, and crystallinity, as well as the decrease in the value of the swelling ratio after adding NCC. This study has revealed that NCC from tea waste can be used to improve the physicochemical properties of PVA film.
\end{abstract}

Keywords: tea waste; nanocrystalline cellulose; poly(vinyl) alcohol; nanocomposites

\section{Introduction}

Polymer nanocomposite films comprise nanofillers dispersed in a polymer matrix. Incorporating some nano-sized fillers can improve the composite properties required for many industrial and technological applications. Polymer nanocomposite films with inorganic fillers can improve stiffness, strength, hardness, and high temperature creep resistance compared to unfilled polymers [1-3]. These nanocomposite films have recently become an issue of great concern from an economic, environmental, and performance point of view. This can be overcome by replacing inorganic fillers with natural materials [4-6].

The organic materials that are often used are natural fibers. Natural fibers generally come from plants and animals. Plant fiber can be further classified into subgroups according to its source, for example, stem, leaf, seed, or fruit. The main component of plant fiber is cellulose, which is a naturally occurring hydrophilic polymer.

Cellulose is a natural biopolymer that is renewable and biodegradable. Cellulose comprises two glucose molecules linked by a -1,4-glycosidic bond [7,8]. Insulating cellulose fibers and reinforcing polymers with them to make nanocomposite films is very advantageous. Fibrils are defined as small, slender fibers or filaments. These may include cellulose crystals or whiskers, and microfibrils [9].

Using various methods, e.g., physical treatments, chemical treatments, and biological treatments, it is possible to obtain cellulose with nanometric dimensions called nanocellulose [10]. Nanocellulose has interesting characteristics; it is lightweight, has high mechanical properties, a high length-to-diameter ratio, and a large specific surface area [11]. Based on ISO (International Organization for Standardization) standards (ISO TS 20477: 2017), nanocellulose can be divided into two categories. The first is cellulose nano-objects, such as cellulose nanocrystals (CNC) and cellulose nanofibrils (CNF). The second type of 
nanocellulose is nanostructured cellulose, which includes cellulose microcrystals (CMC), microcrystalline cellulose (MCC), cellulose microfibrils (CMF), microfibrillated cellulose (MFC), and bacterial cellulose (BC) [12].

Chemical methods, such as strong acid hydrolysis, remove amorphous regions from cellulose fibers and produce nano-sized fibers. Cellulose contains both crystalline and amorphous regions. The crystalline particles obtained after removing the amorphous region via acid hydrolysis treatment are termed nanocrystalline cellulose (NCC). The acid hydrolysis process is conducted using a strong acid solution, such as sulfuric [13] or hydrochloric acid [14]. Because of its superior surface activity and large specific surface area, the addition of NCC can improve the mechanical properties of composites [15]. Oil palm empty fruit bunch pulp [9], bamboo fiber [16], olive fiber [17], pineapple crown waste [18], and tea [19] were used as raw materials to isolate the NCC.

Indonesia is among the world's biggest tea producers. According to the Statista Research Department, in 2020, approximately 127.9 thousand metric tons of tea were produced in Indonesia. A large amount of tea waste is generated during tea processing. Currently, most tea waste is only used for composting or in landfills. However, it has put pressure on the environment because tea waste is difficult to decompose and causes a huge loss of useful components [19]. Therefore, the use of tea waste is currently receiving considerable attention. Tea waste reportedly contains $16.2 \%$ cellulose, $68.2 \%$ hemicellulose, and $18.8 \%$ lignin [20]. Thus, tea waste can be used as a raw material in the manufacture of NCC, which will be a nanofiller in polymer nanocomposite films.

Among various polymers, poly(vinyl) alcohol (PVA) is studied here because it has the specific properties, such as water solubility, semi-crystallinity, non-toxicity, transparency, biocompatibility, and biodegradability [4]. PVA has good chemical and physical stability, and can form fibers, films, and membranes [21]. Due to its excellent film-forming properties in aqueous solvents, PVA-based films can be easily fabricated, and the prepared films have excellent tensile strength, flexibility, and oxygen barrier properties. Thus, PVA-based films have been interesting to observe. However, PVA has poor resistance to wet environments due to its hydrophilic nature, which is caused by the presence of abundant hydroxyl groups. In an aqueous environment, water molecules can easily penetrate the PVA film, causing swelling and thereby destroying its mechanical properties [22]. To overcome the disadvantages of PVA films, nanofiller-based fillers are added. Hence, the combined advantages of nanofillers should be explored.

In this study, the tea waste used to produce NCC is an original and natural material from Indonesia. NCC can be used as filler in nanocomposite films to be applied in the food packaging, pharmaceutical, automobile, and construction industries. That PVA could be manufactured from non-petroleum-based resources has increased worldwide concerns for developing eco-friendly composites. The development of NCC for the reinforcement of nanocomposite films has gained the attention of researchers. The application of nanocomposite films could aid in mitigating environmental impact via diminished dependency on non-renewable products which are derived from fossil fuel resources, such as petroleum and natural gas. With developed PVA-NCC nanocomposite films, the amounts of undegradable residues released into nature would ultimately be reduced.

In this work, NCC was isolated using acid hydrolysis from tea waste. The NCC obtained was used as a nanofiller in manufacturing nanocomposite films. The nanocomposite films were made using a PVA matrix. PVA-NCC nanocomposite films were prepared using the casting method. Thus, in this study, the effects of adding NCC to PVA nanocomposite films were observed on the physicochemical properties. Additionally, the functional groups, morphologies, transparencies, structure crystallinity, mechanical properties, thermal properties, and swelling ratios of PVA-NCC nanocomposite films were also observed. 


\section{Materials and Methods}

\subsection{Materials}

Tea waste was obtained from the production of Perseroan Terbatas Pagilaran, Batang, Central Java, Indonesia. Poly(vinyl) alcohol (PVA) - with a molecular weight of 145,000, sodium hydroxide $(\mathrm{NaOH})$, hydrogen peroxide $30 \%\left(\mathrm{H}_{2} \mathrm{O}_{2}\right)$, glacial acetic acid $\left(\mathrm{CH}_{3} \mathrm{COOH}\right)$, and hydrochloric acid 37\% ( $\mathrm{HCl}$ - -was purchased from Merck, Germany. In addition, sodium hypochlorite $12 \%(\mathrm{NaClO})$ was obtained from Brataco.

\subsection{The Extraction of NCC}

NCC was prepared using acid hydrolysis. Tea waste was sifted using a 100 mesh. The tea waste was treated using a solution of $6 \%(w / v) \mathrm{NaOH}$ at $80^{\circ} \mathrm{C}$ for $3 \mathrm{~h}$. This process was repeated three times, and the solution was washed with distilled water until it obtained a neutral $\mathrm{pH}$. The first bleaching process was conducted using a solution of $2.5 \%(v / v)$ $\mathrm{NaClO}$, coupled with an acetate buffer $(2.7 \mathrm{~g} \mathrm{NaOH}$ and $7.5 \mathrm{~mL}$ of glacial acetic acid in $100 \mathrm{~mL}$ distilled water) [20] stirred at $70{ }^{\circ} \mathrm{C}$ for $1 \mathrm{~h}$, and then washed with distilled water until it obtained a neutral $\mathrm{pH}$. The second bleaching process was conducted using a $7 \%$ $(v / v)$ solution of $\mathrm{H}_{2} \mathrm{O}_{2}$ mixed with a solution of $4 \%(w / v) \mathrm{NaOH}$, stirred at $70{ }^{\circ} \mathrm{C}$ for $2 \mathrm{~h} \mathrm{[4]}$, and then washed with distilled water until it obtained a neutral $\mathrm{pH}$. Acid hydrolysis was conducted using a solution of $5 \mathrm{M} \mathrm{HCl}$ at $50^{\circ} \mathrm{C}$ for $12 \mathrm{~h}$ [23], and then washed with distilled water until it obtained a neutral $\mathrm{pH}$ and NCC was obtained from tea waste in suspension.

\subsection{Preparation of PVA-NCC Nanocomposite Films}

A $10 \%(w / v)$ PVA solution was made by dissolving $1.111 \mathrm{~g}$ of PVA in a $10 \mathrm{~mL}$ mixture of distilled water and NCC suspension and stirring at $1500 \mathrm{rpm}$ at $80^{\circ} \mathrm{C}$ for $3 \mathrm{~h}$. Subsequently, the mixture was formed and dried in an oven at $50^{\circ} \mathrm{C}$ for $24 \mathrm{~h}$. The solvent used was a mixture of distilled water and NCC suspensions (Table 1).

Table 1. The ratios of NCC suspension and distilled water used.

\begin{tabular}{ccccccccc}
\hline Label & PNC0 & PNC0.5 & PNC1 & PNC2 & PNC3 & PNC4 & PNC5 & PNC6 \\
\hline NCC suspension $(\mathrm{mL})$ & 0 & 0.5 & 1 & 2 & 3 & 4 & 5 & 6 \\
\hline Distilled water $(\mathrm{mL})$ & 10 & 9.5 & 9 & 8 & 7 & 6 & 5 & 4 \\
\hline
\end{tabular}

\subsection{Characterizations}

\subsubsection{Fourier Transform Infrared Spectroscopy (FTIR)}

FTIR (Thermo Nicolet iS10, Tokyo Japan) analysis was used to observe changes in the functional group at each treatment, and changes in the composition of NCC when added to nanocomposite films. The wavenumbers used were between $400 \mathrm{~cm}^{-1}$ and $4000 \mathrm{~cm}^{-1}$.

\subsubsection{Raman Spectroscopy}

The Raman spectra of the nanocomposite films were measured using a Raman spectrometer (Thorlabs CCS100, Newton, NJ, USA) with an excitation laser of $532 \mathrm{~nm}$ and a resolution of $10 \mathrm{~cm}^{-1}$. The wavenumbers used were between $400 \mathrm{~cm}^{-1}$ and $4000 \mathrm{~cm}^{-1}$.

$$
\text { Degree of crystallinity of PVA }=\frac{I_{(\mathrm{O}-\mathrm{H})}}{I_{(\mathrm{C}-\mathrm{H})}}
$$

where $I_{(\mathrm{O}-\mathrm{H})}$ is the intensity of $\mathrm{O}-\mathrm{H}$, and $I_{(\mathrm{C}-\mathrm{H})}$ is the intensity of C-H.

\subsubsection{Morphology Analysis}

The influence of each NCC manufacturing process and the effect of adding NCC to nanocomposite films was analyzed using a scanning electron microscope (Jeol JSM-6510LA, Tokyo, Japan) with an accelerating voltage of $10-15 \mathrm{kV}$. The samples were mounted on metal studs using double-sided adhesive tapes. The samples were coated using platinum to avoid 
charging during the tests. The diameter size and morphology of the NCC were determined using a transmission electron microscope (Jeol Jem-1400, Tokyo, Japan). The diameter size distribution of the NCC was calculated using ImageJ software version 2006 (National Institutes of Health (NIH), Bethesda, MD, USA).

\subsubsection{Crystallographic Analysis}

The crystallinity of the nanocomposite films was measured using an X-ray diffractometer (PANalytical Type X'Pert Pro, Tokyo, Japan) with $\mathrm{Cu}-\mathrm{K} \alpha$ radiation at $\lambda=0.154 \mathrm{~nm}$. The XRD data were taken in the range of $2 \theta=5-60^{\circ}$. The crystalline index (CI) was calculated using Equation (2) [24]:

$$
C I=\frac{I_{002}-I_{a m}}{I_{002}} \times 100
$$

where $I_{002}$ is the maximum intensity of the crystalline regions, and $I_{a m}$ is the lowest intensity of the amorphous regions in the sample. The degrees of crystallinity of the nanocomposite films were calculated using Herman's equation, and the CI was calculated using Equation (3) [25]:

$$
C I=\frac{A_{c r}}{A_{t}} \times 100
$$

where $A_{c r}$ is the crystalline area, and $A_{t}$ is the total area of the diffractogram.

\subsubsection{Analysis of Thermal Properties}

The thermal properties of the nanocomposite films were assessed using differential scanning calorimetry (Shimadzu DSC 60 Series, Tokyo, Japan). A total of $10 \mathrm{mg}$ of the sample was prepared, placed in an aluminum container, and pressed with the aluminum container into pellets. The device was set at $30^{\circ} \mathrm{C}-400^{\circ} \mathrm{C}$ with a $10^{\circ} \mathrm{C} / \mathrm{min}$ rise in nitrogen atmosphere.

\subsubsection{Transparency of the Nanocomposite Film}

The transparency of the nanocomposite films was measured using a UV-Vis spectrophotometer (Ocean Optics USB4000, Dunedin, FL, USA) via the ASTM standard D1003-00 method, with a transmittance between $400 \mathrm{~nm}$ and $800 \mathrm{~nm}$. Measurement was repeated three times [23].

\subsubsection{Swelling Ratios of the Nanocomposite Film}

The swelling behaviors of the nanocomposite films were observed by cutting the nanocomposite into a square shape, sized $10 \mathrm{~mm} \times 10 \mathrm{~mm}$. Subsequently, the initial weight $\left(W_{0}\right)$ was measured before the sample was soaked in distilled water for $24 \mathrm{~h}$. The sample was drained slowly on filter paper to remove excess water from the nanocomposite's surface, and the sample was weighed when wet $(W)$. The swelling ratio was calculated using Equation (4) [26]:

$$
\text { Ratio swelling }=\left(\frac{W-W_{0}}{W_{0}}\right) \times 100
$$

The experiment was repeated three times.

\subsubsection{Analysis of Mechanical Properties}

The mechanical properties (tensile strength, Young's modulus, and elongation at break) of the nanocomposite films were observed using a universal testing machine (Zwick DO-FB.5TS, Kennesaw, GA, USA). Samples were cut following ASTM standard D638 type V. 


\subsubsection{Statistical Analysis}

The statistical significance of the tensile strength, elastic modulus, elongation at break, opacity, and swelling ratio values for nanocomposite films were verified using mean \pm standard deviation (SD) and one-way variant analysis (ANOVA). The Tukey method was used to test mean differences. Statistical significance was considered as $p<0.05$.

\section{Results}

\subsection{FTIR and Raman Analysis}

The FTIR spectra of any chemical treatment on tea waste and nanocomposite films are shown in Figure 1a,b. The FTIR spectra of any chemical treatment of tea waste (Figure 1a) showed a broad peak at $3408 \mathrm{~cm}^{-1}$ due to the bonded $\mathrm{O}-\mathrm{H}$ group in the cellulose molecules [27]. The peak intensity of the O-H group was found to be lower in the tea waste due to the presence of non-cellulose components that were still contained. Then, the peak intensity of the O-H group increased after alkali treatment, bleaching, and hydrolysis, which indicated an increased cellulose content. The peak at $2922 \mathrm{~cm}^{-1}$ was related to the stretching vibration of the $\mathrm{C}-\mathrm{H}$ produced by the methyl, and methyl groups, in cellulose, hemicellulose, and lignin [28]. The peak at $898 \mathrm{~cm}^{-1}$ corresponds to the $-\mathrm{CH}_{2}$ of glycosidic $\beta$ in cellulose [20]. The alkali treatment was performed to remove remnants of lignin and hemicellulose, as evidenced by the decreasing transmittance intensity at $898 \mathrm{~cm}^{-1}$. A stretching vibration related to C-O was observed at $1033 \mathrm{~cm}^{-1}$ [29]. The peak at $1047 \mathrm{~cm}^{-1}$ was related to the stretching vibration of the C-O-C from both the hemicellulose and cellulose $[18,30]$. The $C=C$ stretching vibration at $1638 \mathrm{~cm}^{-1}$ indicates an aromatic group in lignin still present in tea waste [19]. The transmittance peak intensity at $1638 \mathrm{~cm}^{-1}$ was decreased, indicating that the lignin content was minimized after chemical treatment.

Figure $1 \mathrm{~b}$ shows the FTIR spectra of the nanocomposite films. The peak at $3419 \mathrm{~cm}^{-1}$ was related to the stretching vibration of the O-H from the intermolecular and intramolecular hydrogen bonds between the hydroxyl groups of PVA and NCC (Figure 2) [31]. Adding NCC to the PVA matrix generates a much sharper stretching peak with higher intensity, presumably due to the contribution of O-H groups from NCC. In fact, interaction through hydrogen bonding involving NCC and the PVA matrix is likely to contribute to the broadening of the O-H band. The presence of NCC in the nanocomposite films shifts this band, presumably due to intermolecular hydrogen bonding interactions with O-H groups on the surface of NCC [32]. The peak at $2922 \mathrm{~cm}^{-1}$ was related to the stretching vibrations of the $\mathrm{C}-\mathrm{H}$, which is an aliphatic cluster in nanocomposite films [33]. It decreased in intensity as the NCC increased, which can be explained by the contribution of the $\mathrm{C}-\mathrm{H}$ vibration from NCC in the nanocomposite films. The peak at $1737 \mathrm{~cm}^{-1}$ was related to the $\mathrm{C}=\mathrm{O}$ of acetate group residues in the PVA matrix [34]. The $\mathrm{C}=\mathrm{O}$ stretching vibration was present in the NCC, thus confirming the reaction between the NCC and the PVA. The peak at $1085 \mathrm{~cm}^{-1}$ represents the C-O-C stretching of the pyranose ring derived from NCC. This peak was formed when NCC was added to the PVA matrix [11]. However, the intensity of that peak was reduced when NCC was added. 


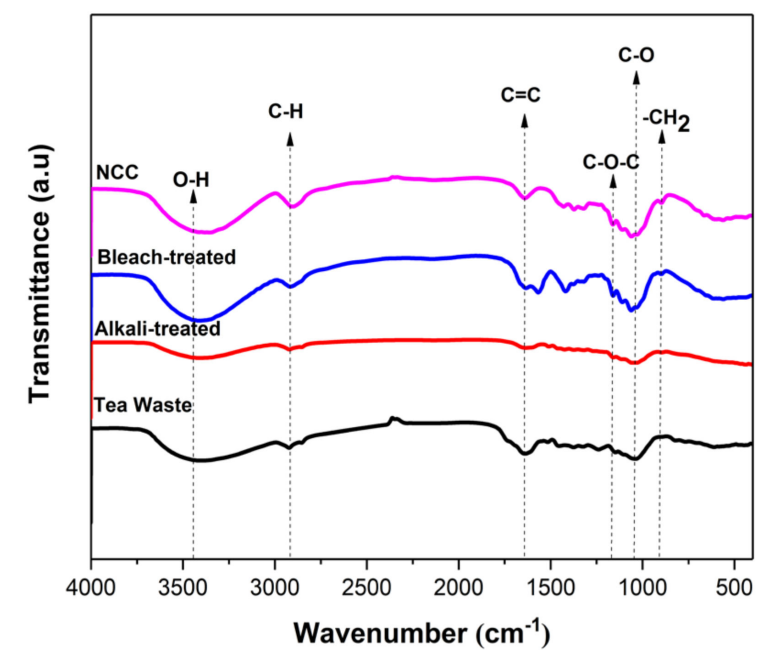

(a)

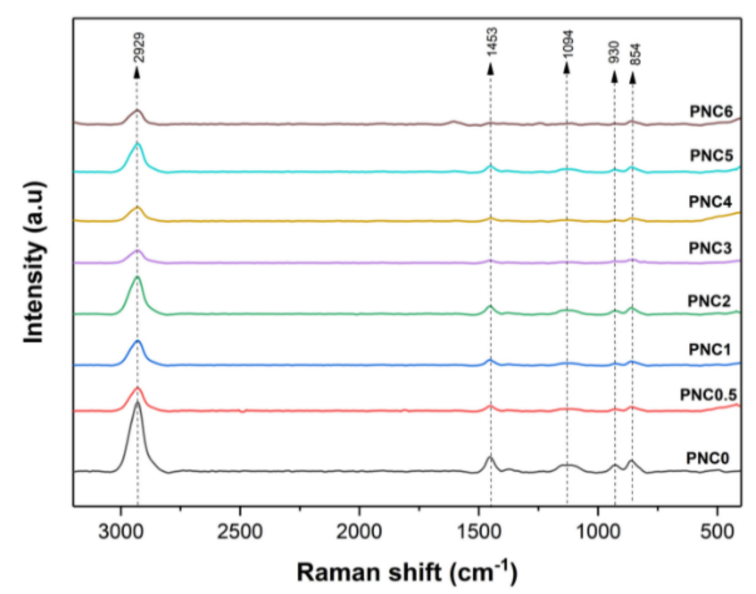

(c)

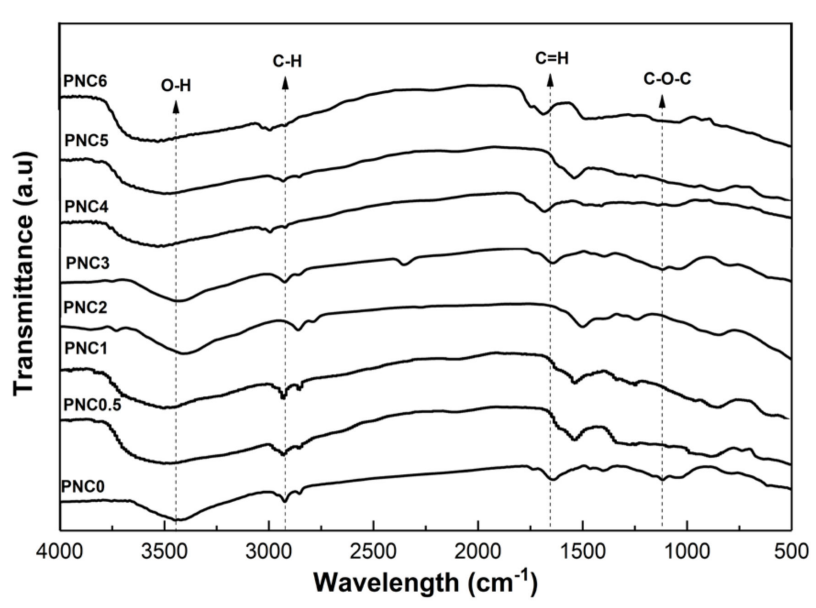

(b)

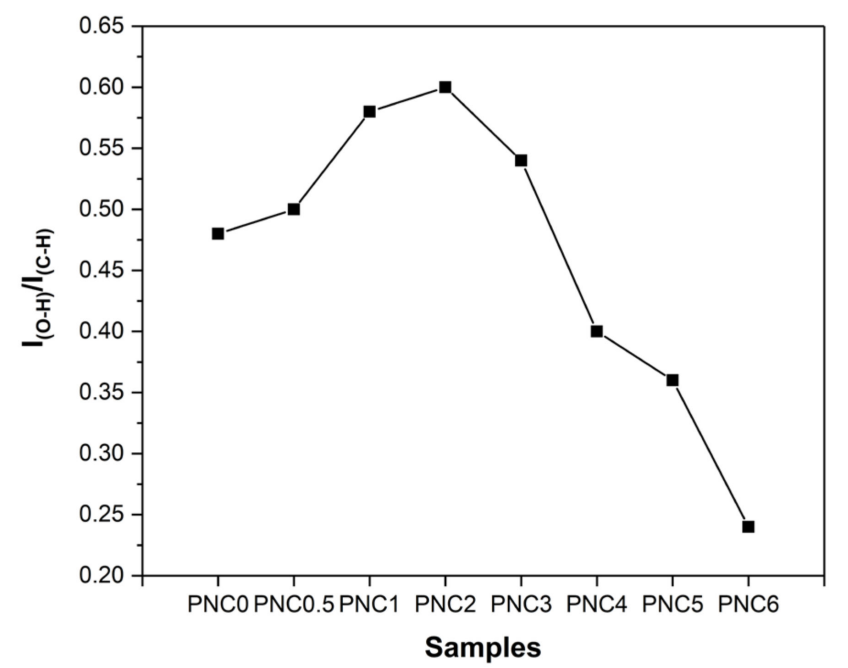

(d)

Figure 1. (a) FTIR spectra of any chemical treatment of tea waste. (b) FTIR spectra of PVA-NCC nanocomposite films. (c) Raman spectra of PVA-NCC nanocomposite films. (d) Intensity ratios of $I_{(\mathrm{O}-\mathrm{H})} / I_{(\mathrm{C}-\mathrm{H})}$ PVA-NCC nanocomposite films.

The Raman spectroscopy of the nanocomposite films is shown in Figure 1c. The peaks at $2929 \mathrm{~cm}^{-1}, 1453 \mathrm{~cm}^{-1}, 930 \mathrm{~cm}^{-1}$, and $854 \mathrm{~cm}^{-1}$ are characteristic of PVA. There was a decrease in peak size at $2929 \mathrm{~cm}^{-1}$ after adding NCC. This indicated that the chain structure of PVA changed with the addition of NCC. These changes were the result of the intermolecular complex formed due to the hydrogen bonds between PVA and NCC [25]. The peak at $1094 \mathrm{~cm}^{-1}$ indicated the $\mathrm{C}-\mathrm{O}$ stretching and $\mathrm{O}-\mathrm{H}$ bending from the amorphous sequence of PVA. The peak at $854 \mathrm{~cm}^{-1}$ indicated $-\mathrm{CH}_{2}$ rocking in the PVA. The peak at $1094 \mathrm{~cm}^{-1}$ was associated with the PVA amorphous regions, and this peak was influenced by the addition of NCC. Variations in the intensity ratio of $I_{(\mathrm{O}-\mathrm{H})} / I_{(\mathrm{C}-\mathrm{H})}$ indicated the degree of PVA crystallinity. There was an increase and then a decrease in the intensity ratio upon adding NCC (Figure 1d). The degree of crystallinity of the PVA-NCC nanocomposite was reduced by the rate of NCC reinforcement. This was due to the limited mobility of the PVA molecular chain in nanocomposite films [32]. 

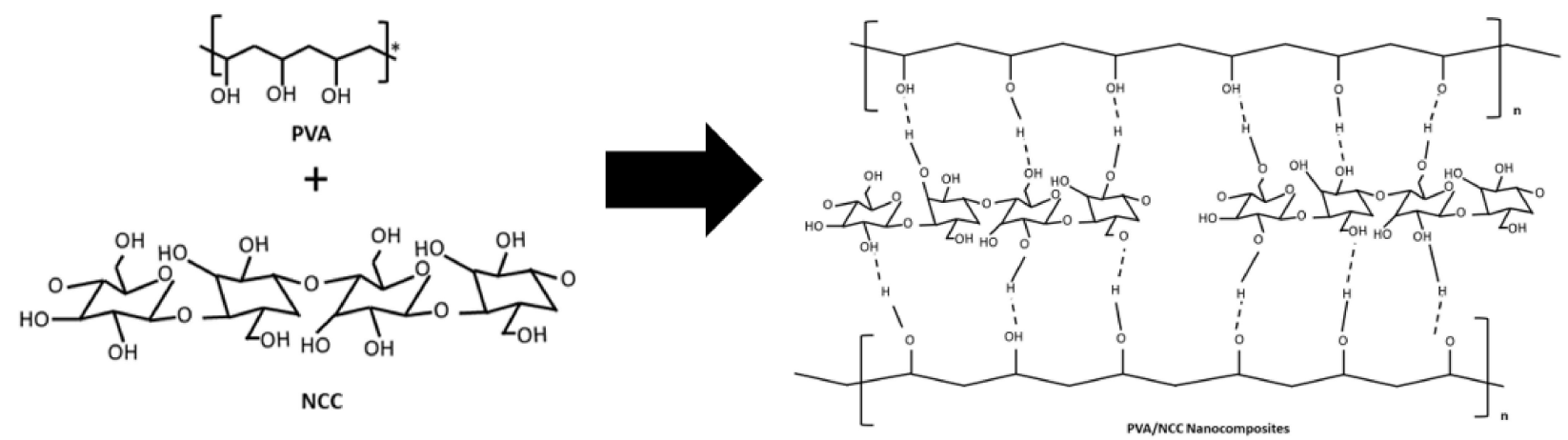

Figure 2. Schematic to show the intermolecular complex formed due to the hydrogen bonds between PVA and NCC.

\subsection{Morphology Analysis}

The morphology of any chemical treatment of tea waste and PVA-NCC nanocomposite films is shown in Figures 3-5. Figure 3a shows that the morphology of the tea waste is not uniform; some particles are in the form of long fibers and irregular shapes. This can happen because tea is produced from the leaves and stems of the tea plant. Cellulose in tea waste is still encased by non-cellulose components, such as lignin and hemicellulose. In the alkali treatment process, non-cellulose components begin to decompose. Lignin and hemicellulose decompose due to alkali treatment (black circles in Figure 3b). The sample surface became more irregular and flaky after alkali treatment [13]. This process helps with fiber decomposition and defibrillation [35]. The bleach-treated tea waste demonstrated smooth, clear, and individualized rod-like fibers of cellulose (white arrow in Figure 3c), which is indicative of the complete removal of non-cellulose components [36].

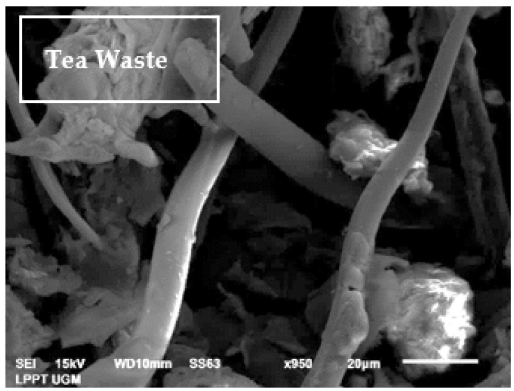

(a)

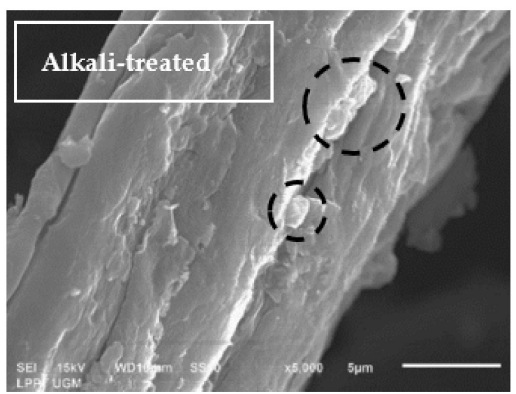

(b)

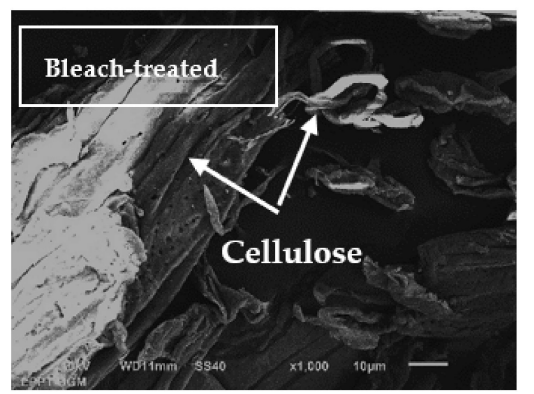

(c)

Figure 3. SEM micrographs of (a) tea waste, (b) alkali-treated tea waste, and (c) bleach-treated tea waste.

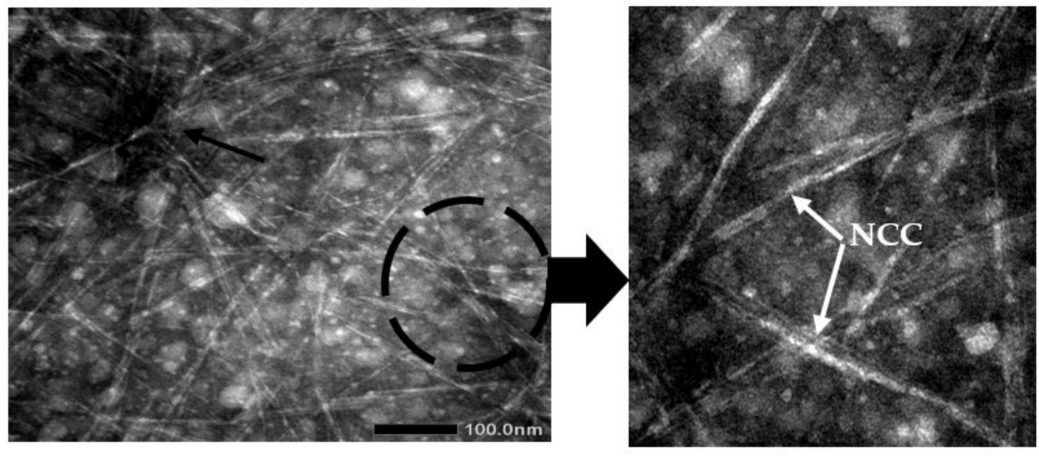

(a)

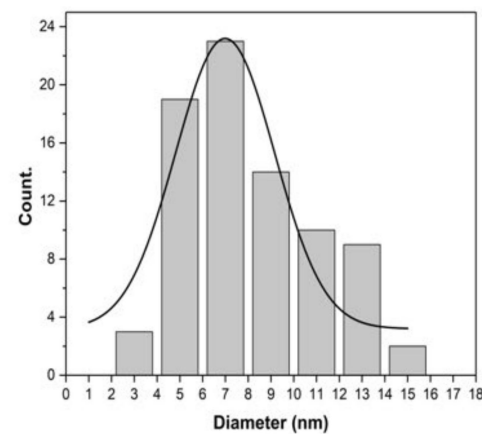

(b)

Figure 4. (a) TEM micrograph of NCC extracted from tea waste. (b) Diameter distribution of NCC extracted from tea waste. 

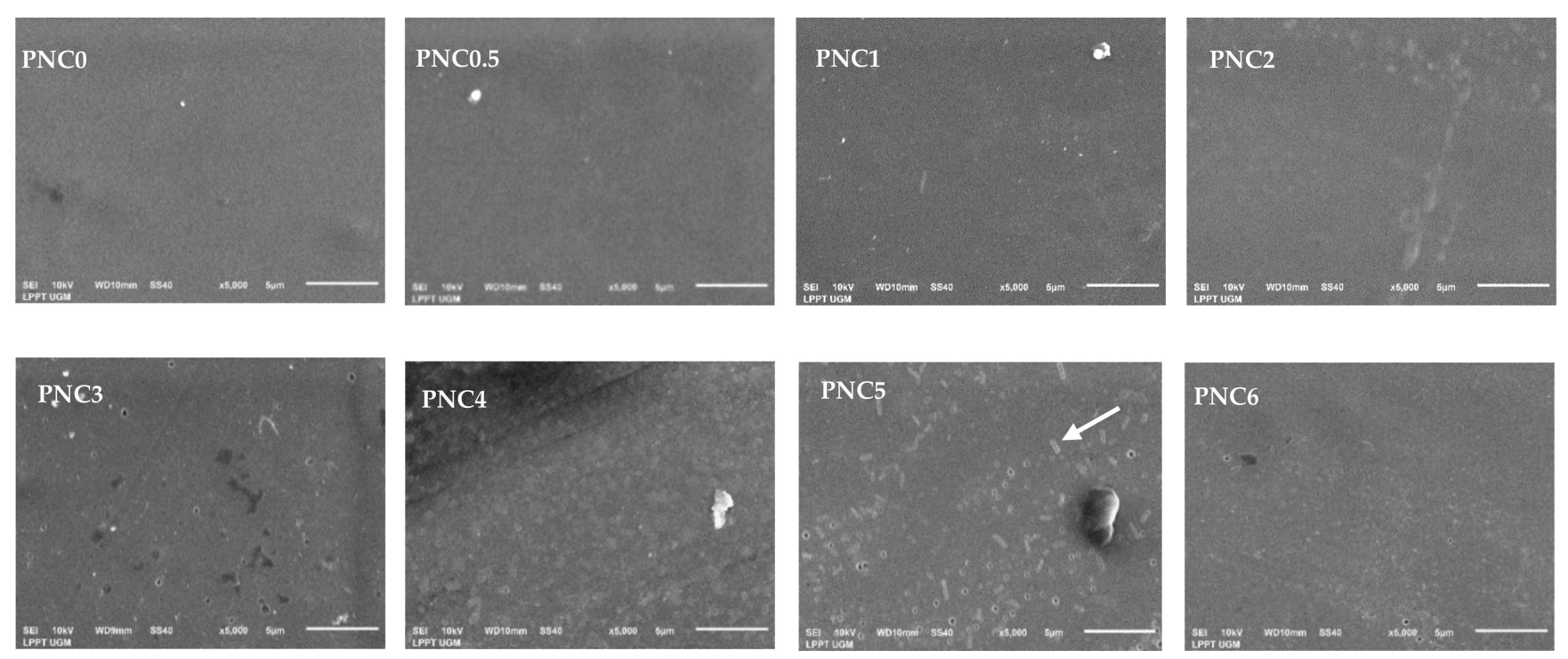

Figure 5. SEM micrographs of PVA-NCC nanocomposite films.

The NCC can be decomposed through acid hydrolysis (black circle in Figure 4a). This can occur when strong acids are used during acid hydrolysis [37]. Acid hydrolysis allows for the elimination of the amorphous area of tea waste cellulose fibers by unraveling the cellulose microfibril of tea waste into NCC (white arrow in Figure 4a). Utilizing acid hydrolysis significantly alters the cellulose content of tea waste. The shape of the NCC particles is thought to be due to an imperfect cooling process (quenching) during the cessation of acid hydrolysis [20]. The rest of the acid hydrolysis solution still reacts with tea waste cellulose during the cooling process, thus changing the shape from that of NCC fibers to a nanoparticle shape. During this process, there is also an agglomeration (black arrow in Figure 4a). This agglomeration possibly occurs due to the charge of ions on the surface of the crystalline area as a result of acid hydrolysis. Figure $4 \mathrm{~b}$ shows the distribution of the sizes of the NCC; diameters ranged from $3.63 \mathrm{~nm}$ to $14.95 \mathrm{~nm}$, with an average of $6.99 \pm 0.50 \mathrm{~nm}$.

The morphology of the nanocomposite films is shown in Figure 5. The PVA film surface looks smooth and uniform before the NCC suspension is added, and there is an increase in surface roughness after the addition of NCC [38]. The even and uniform distribution of NCC in the matrix can improve the mechanical properties of nanocomposite films (white arrow in Figure 5). However, when the NCC concentration was increased, small particles appeared in the PVA composite film due to agglomeration. This can be seen clearly in the PVA nanocomposite film. The NCC distribution in the PVA matrix became increasingly uneven, resulting in a large decrease in light transmission and a negative effect on the mechanical properties of the PVA-NCC nanocomposite film. This was demonstrated in the UV-Vis spectroscopy and tensile test results [39].

\subsection{Crystallographic Analysis}

The degree of crystallization after each chemical treatment of tea waste, and the influence of NCC on the crystal structure of the nanocomposite films, were determined. Figure 6a shows the effect of the chemical treatment of tea pulp on the XRD peak. Peaks of $15.2^{\circ}, 22^{\circ}$, and $34.4^{\circ}$ with fields (110), (200), and (004) indicate cellulose $\beta$ phases [31,40]. The crystalline structure of the NCC was at about $2 \theta=22^{\circ}$, and the amorphous area was at about $2 \theta=15.2^{\circ}$. Table 2 shows the crystallinity of tea waste at different stages of chemical treatments. Increased crystallinity indicates that the lignin and hemicellulose content in each treatment was reduced [41]. Materials with high crystallinity tend to have high mechanical properties, and this is important for applications in amplifiers based on nanocomposites [18]. 


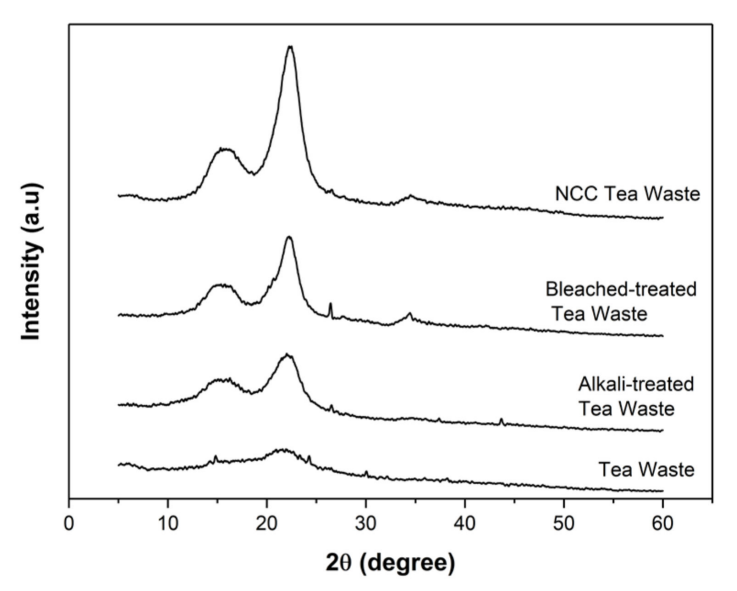

(a)

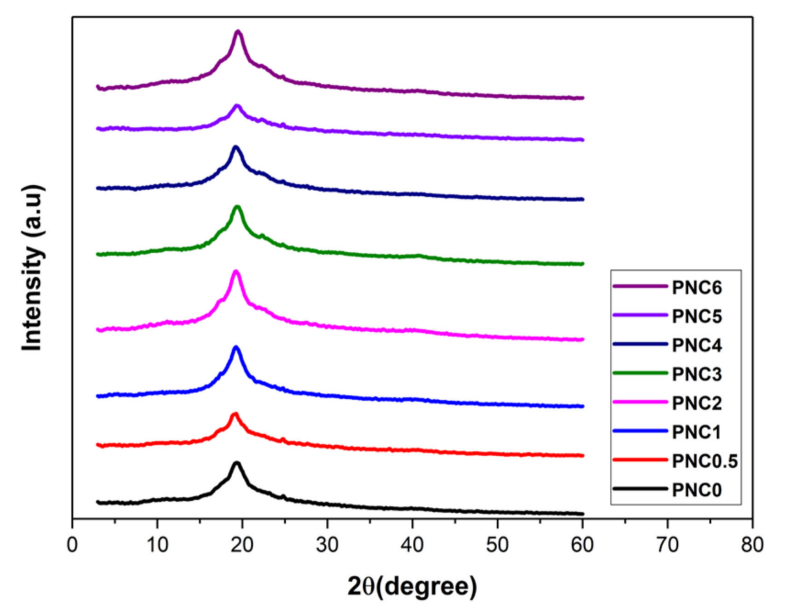

(b)

Figure 6. XRD diffractograms of (a) the chemical treatment process of tea waste and (b) PVA-NCC nanocomposite films.

Table 2. The crystallinity index of tea waste at different stages of chemical treatment.

\begin{tabular}{lccccc}
\hline \multirow{2}{*}{ Sample } & \multicolumn{2}{c}{ Amorphous } & \multicolumn{2}{c}{$(\mathbf{0 0 2})$} & \multirow{2}{*}{$\boldsymbol{C I}(\mathbf{\%})$} \\
\cline { 2 - 5 } & $\mathbf{2 \theta}\left(^{\circ}\right)$ & $\boldsymbol{I}_{\boldsymbol{a m}}$ & $\mathbf{2 \theta}\left(^{\circ}\right)$ & $\boldsymbol{I}_{002}$ & \\
\hline Tea waste & 15.2 & 109 & 21.7 & 201 & 45.8 \\
Alkali-treated tea waste & 15.6 & 269 & 22 & 493 & 46.3 \\
Bleach-treated tea waste & 15.7 & 287 & 22.08 & 657 & 56.3 \\
NCC tea waste & 16.1 & 457 & 22.2 & 1263 & 63.8 \\
\hline
\end{tabular}

Figure $6 \mathrm{~b}$ shows the crystalline structure of the nanocomposite films. The peak characteristic of PVA at $19.4^{\circ}$ demonstrates that the field (110) of the partially hydrolyzed PVA semi-crystalline region has a lower crystallinity compared to pure PVA crystals. The addition of NCC into the PVA nanocomposite film slightly reduced the intensity of the field (110). The crystallinity of the PVA film increases as the NCC is added [42]. Crystalline nanocomposite films are shown in Table 3 . The maximum crystallinity was $39.5 \%$, as seen in PNC1. The increased crystallization due to the bonding of NCC and PVA was evenly distributed [43]. A decreased crystallinity indicates that some hydrogen bonds between PVA chains are substituted with PVA-NCC hydrogen bonds. NCC has a higher crystallinity compared to PVA; therefore, by increasing the quantity of NCC, the crystallinity of the nanocomposite films also increases [44].

Table 3. The physicochemical properties of PVA-NCC nanocomposite films.

\begin{tabular}{ccccccc}
\hline Label & $\begin{array}{c}\mathbf{C I} \\
\mathbf{( \% )}\end{array}$ & $\begin{array}{c}\text { Opacity } \\
\text { Value } \\
\mathbf{( a u . n m )}\end{array}$ & $\begin{array}{c}\text { Swelling Ratio } \\
\mathbf{( \% )}\end{array}$ & $\begin{array}{c}\mathbf{T}_{\mathbf{m} \mathbf{1}} \\
\mathbf{(} \mathbf{C})\end{array}$ & $\begin{array}{c}\mathbf{T}_{\mathbf{m} \mathbf{2}} \\
\left({ }^{\circ} \mathbf{C}\right)\end{array}$ & $\begin{array}{c}\Delta \mathbf{H}_{\mathbf{m}} \\
(\mathbf{J} / \mathbf{g})\end{array}$ \\
\hline PNC0 & 29.7 & $14.3 \pm 0.1$ & $258.8 \pm 15.2$ & 227.3 & 339 & 52.8 \\
PNC0.5 & 24.3 & $45.1 \pm 0.1$ & $245.9 \pm 29.3$ & 225.9 & 349.5 & 44.9 \\
PNC1 & 39.5 & $74.9 \pm 0.4$ & $234.1 \pm 9.4$ & 225.2 & 338.1 & 73.4 \\
PNC2 & 35.3 & $112.9 \pm 1.7$ & $226.7 \pm 29.9$ & 224.8 & 348.9 & 59.1 \\
PNC3 & 34.6 & $177.2 \pm 2.5$ & $226.2 \pm 17.7$ & 225.3 & 350 & 58.4 \\
PNC4 & 32.8 & $252.1 \pm 2.5$ & $225.2 \pm 18.7$ & 223.8 & 345.3 & 59.5 \\
PNC5 & 29.8 & $301.9 \pm 0.9$ & $220.7 \pm 9.4$ & 223.7 & 347.9 & 53 \\
PNC6 & 24.3 & $345.8 \pm 1.2$ & $193.4 \pm 16.4$ & 223.2 & 347.3 & 37 \\
\hline
\end{tabular}




\subsection{Analysis of Thermal Properties}

The thermal properties of the nanocomposite films are presented in Figure 7. The melting point, degradation, glass transition temperatures, and enthalpy of the nanocomposite films are shown in Table 3 . The peak at $100-150{ }^{\circ} \mathrm{C}$ shows an endothermic peak, which indicated that the heat energy was used to evaporate the water contained in the nanocomposite films. The nanocomposite films have two melting points, namely $\mathrm{T}_{\mathrm{m} 1}$ and $\mathrm{T}_{\mathrm{m} 2} . \mathrm{T}_{\mathrm{m} 1}$ is the melting point of PVA film. $\mathrm{T}_{\mathrm{m} 1}$ was between $223.17^{\circ} \mathrm{C}$ and $227.32{ }^{\circ} \mathrm{C}$. The effect of adding the NCC, which lowers the value of $\mathrm{T}_{\mathrm{m} 1}$, can be inferred from the results of the DSC. In PNC0, the melting point of the PVA was $227.32{ }^{\circ} \mathrm{C}$, and after the addition of NCC, $\mathrm{T}_{\mathrm{m} 1}$ decreased. This can occur due to the strong interaction between the NCC and the PVA matrix, which damages the molecular chain structure. The reduction in the melting point can also result from the strong interaction between the polymer matrix and the hydroxyl group of the NCC [11]. $\mathrm{T}_{\mathrm{m} 2}$ is the nanocomposite film degradation. Adding NCC generally increases $T_{m 2}$. At $T_{m 2}$, the temperature exceeds $300{ }^{\circ} \mathrm{C}$, indicating that the NCC in nanocomposite films begins to degrade [4].

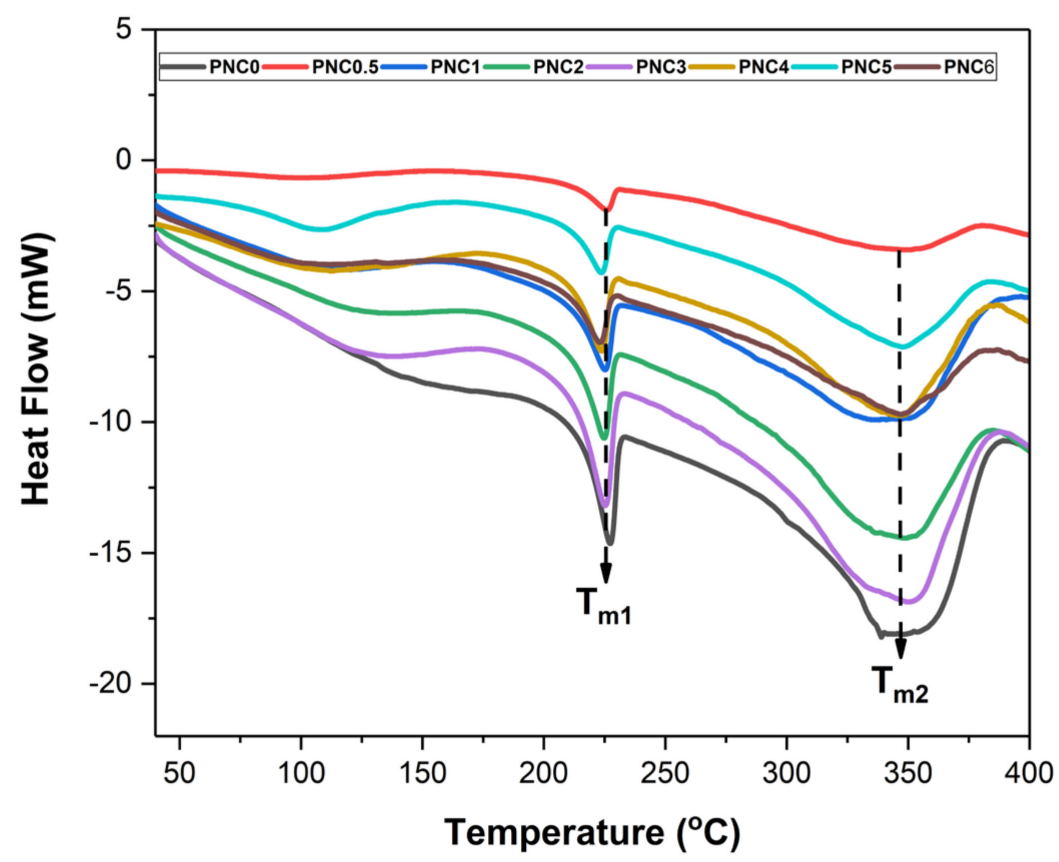

Figure 7. DSC curves of PVA-NCC nanocomposite films.

The addition of NCC also increased the melt enthalpies $\left(\Delta \mathrm{H}_{\mathrm{m}}\right)$ of nanocomposite films, indicating that the addition of NCC improves the crystal structure of PVA [45]. This is because the addition of NCC damages the crystalline structure of the PVA. The chain interactions in PVA and NCC were weakened, and the crystallinity of the nanocomposite films decreased.

\subsection{Transparency of the Nanocomposite Films}

The change in the transparency of the nanocomposite films upon adding NCC is shown in Figure 8a. The increasing content of NCC in PVA film decreased transparency and increased opacity (Table 3) [46]. The opacity values obtained ranged from PNC0 (12.62 au.nm) to PNC6 (307.79 au.nm). This was confirmed using a UV-Vis spectroscopy (Figure $8 b$ ), with a lower transmittance value in the nanocomposite films than in the PVA film, but with the same wavelength [14]. The transmittance value (Figure 8c) of the nanocomposite films was influenced by NCC distribution factors, such as the occurrence of agglomeration. This is consistent with the SEM test results. The addition of NCC resulted in the scattering of light, resulting in low transparency. 

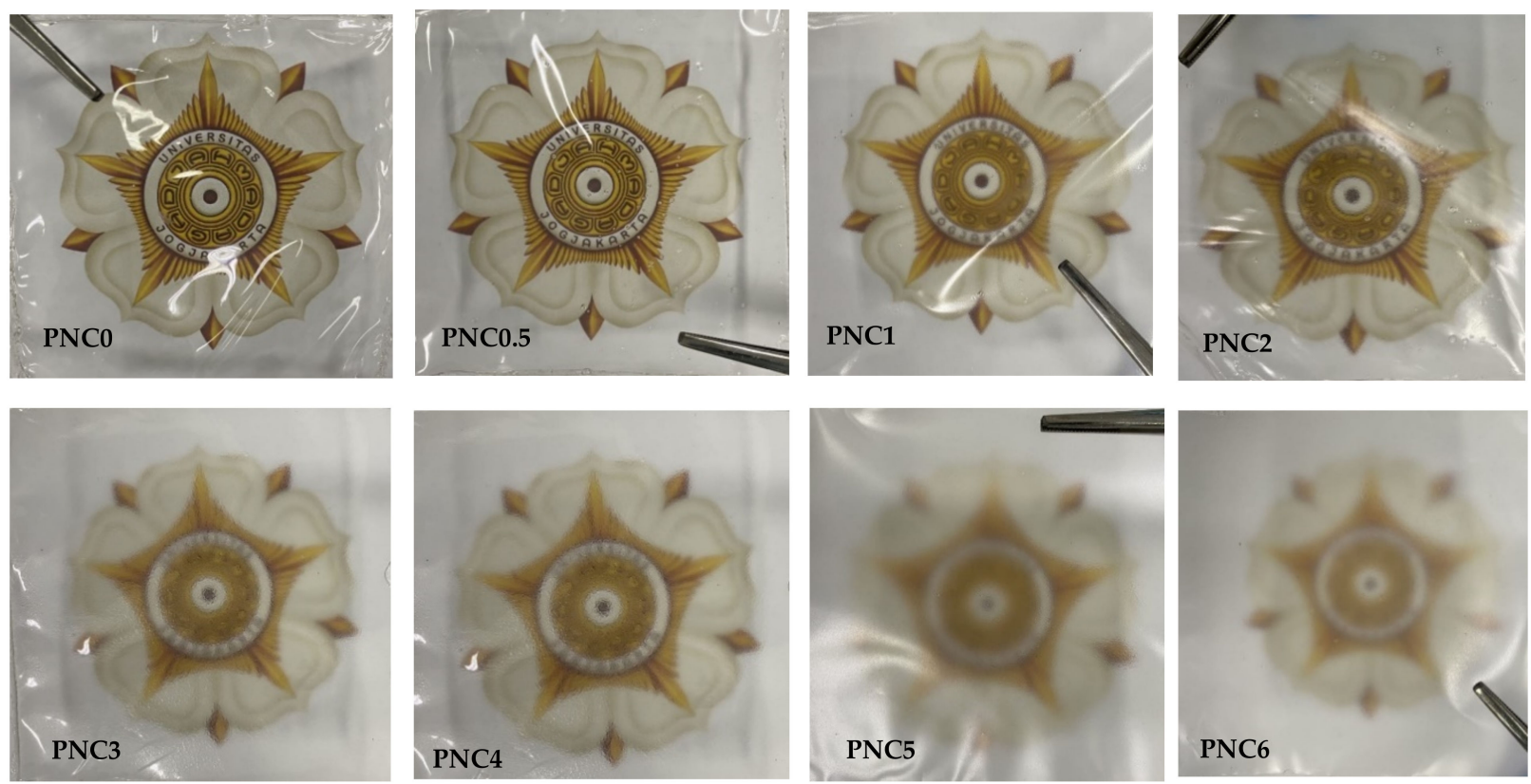

(a)

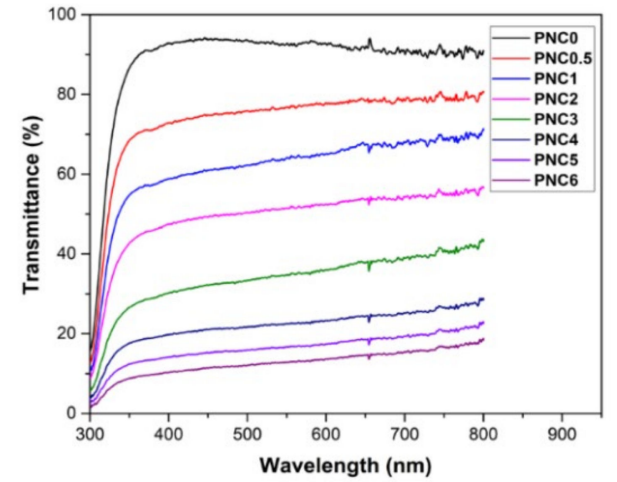

(b)

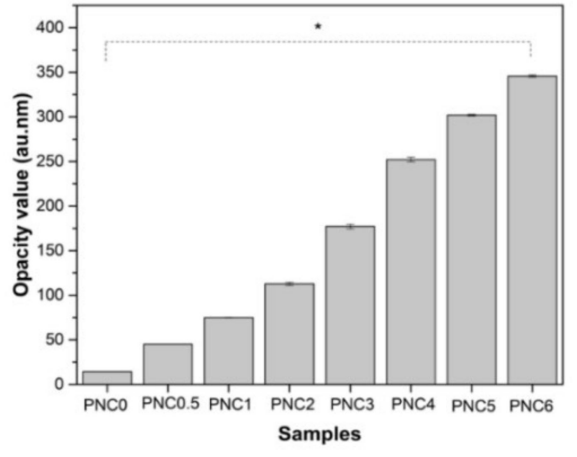

(c)

Figure 8. (a) Images of PVA-NCC nanocomposite films. (b) The transmittance values of PVA-NCC nanocomposite films. (c) The opacity values of PVA-NCC nanocomposite films $\left({ }^{*}: p<0.05\right)$.

The opacity value of nanocomposite films could provide information on the size of the added materials dispersed within the PVA matrix during the formation of nanocomposite films. It could also be an indicator of the number of pores within the nanocomposite films [47]. If NCC had smaller particle sizes, it would fill the pores of the PVA matrix, which would induce a reduction in the light pathway, causing the nanocomposite films to have a high opacity value.

\subsection{Swelling Ratios of Nanocomposite Films}

The swelling ratios of the nanocomposite films are shown in Figure 9. The swelling ratio decreased when NCC was added. The swelling ratio decreased from PNC0 (256\%) to PNC6 (193\%) (Table 3). Furthermore, the swelling ratio was controlled by the hydrophilic ability of the functional groups. The addition of NCC decreases the availability of functional groups in the matrix that can interact with water [48]. The interaction between the hydrophilic groups of NCC and PVA caused a decrease in osmotic pressure swelling, resulting in a decreased amount of water in the nanocomposite films. The increase in NCC resulted in stacking in tissue gaps and a decreased ability to absorb water [49]. 


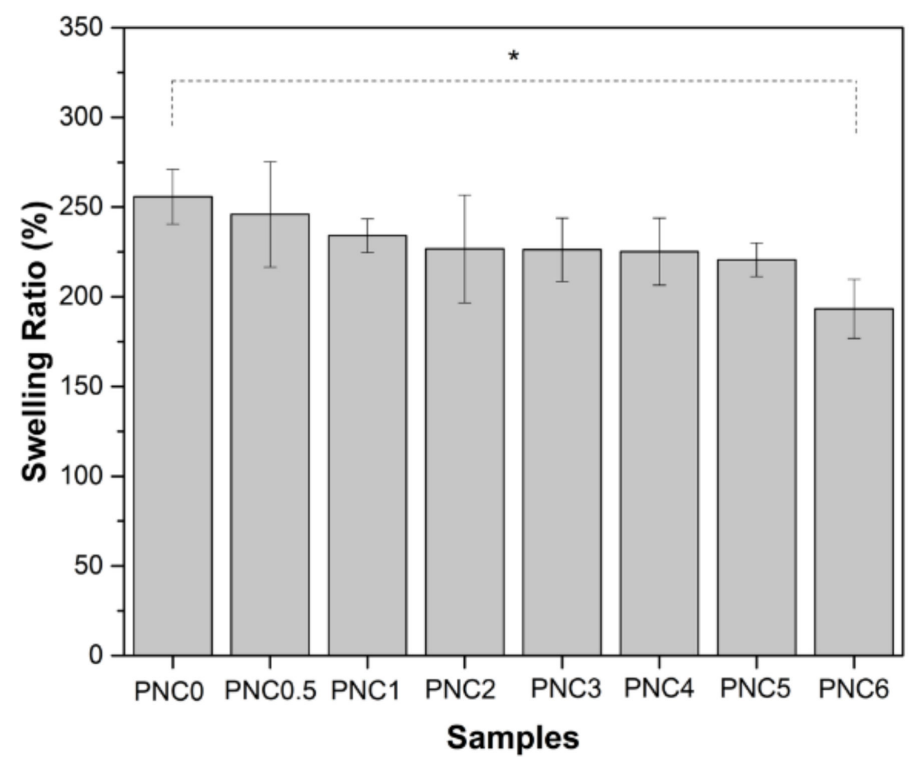

Figure 9. The swelling ratios of PVA-NCC nanocomposite films $\left({ }^{*}: p<0.05\right)$.

The swelling ratios of the nanocomposite films decreased with increasing NCC quantities. It is clear that as NCC increases, the equilibrium solvent uptake decreases. This is due to the increased hindrance exerted by the crystals at higher loadings.

\subsection{Analysis of Mechanical Properties}

The mechanical properties were assessed using the tensile test standard, ASTM D-638 type V. Figure 10a shows the continuous loading results in nanocomposite samples during the deforming process. Figure 10b-d show the tensile strength, Young's modulus, and elongation at the break of the nanocomposite films.

The tensile strengths of the nanocomposite films are shown in Figure 10b. Their tensile strength increased after NCC was added to the PVA matrix. Compared to the tensile strength of PNC0 (25.3 MPa), the tensile strength of PNC2 (40.3 MPa) increased. This increase is due to the interaction of hydrogen bonds occurring between NCC and PVA, an equitable nanofiber distribution, and compatibility between the fibers and the PVA matrix [34]. The dispersion of fibers increases the number of intermolecular bonds between the nanofibers and the PVA matrix. The decreased tensile strength of nanocomposite films may occur due to the agglomeration of NCC and the uneven distribution of nanofillers in the PVA matrix [50]. The agglomerated NCC creates imperfections in the PVA matrix and causes early failure. Agglomeration decreases interfacial adhesion between NCC and the PVA matrix [51]. The decrease in tensile strength could also be due to the formation of air bubbles during the sample molding process and pore formation in nanocomposite films (blue arrow in Figure 5).

The Young's modulus of the nanocomposite is shown in Figure 10c. The pattern of changes in Young's modulus, with increasing NCC content, resembles changes in tensile strength. Young's modulus increased significantly from PNC0 (219.2 $\mathrm{MPa})$ to PNC2 (581.4MPa). The increase in Young's modulus can be attributed to the formation of the network structure generated by the interaction of the NCC and the PVA matrix via hydrogen bonding. However, in PNC3 (372.1), Young's modulus began to decrease. The decrease in Young's modulus can be explained by the difference in the failure strain between the NCC and PVA matrices. In other words, NCC reinforcement does not apply when the failure strain of the PVA matrix is much larger than that of the NCC.

The elongation at the break of the nanocomposite films is shown in Figure 10d. This study found that elongation at the break of nanocomposite films increased with the increasing addition of NCC in PNC2 (176.2\%) and started to decrease in PNC4 (84.7\%). This 
decrease was due to the incorporation of the NCC and PVA matrices, which may fail to form hydrogen bonds either intramolecularly or intermolecularly, thereby losing tensile strength, and hydrogen bond formation between the PVA chains is disturbed due to the presence of NCC particles [34]. Overall, it can be said that adding NCC improves the mechanical properties of the PVA matrix.

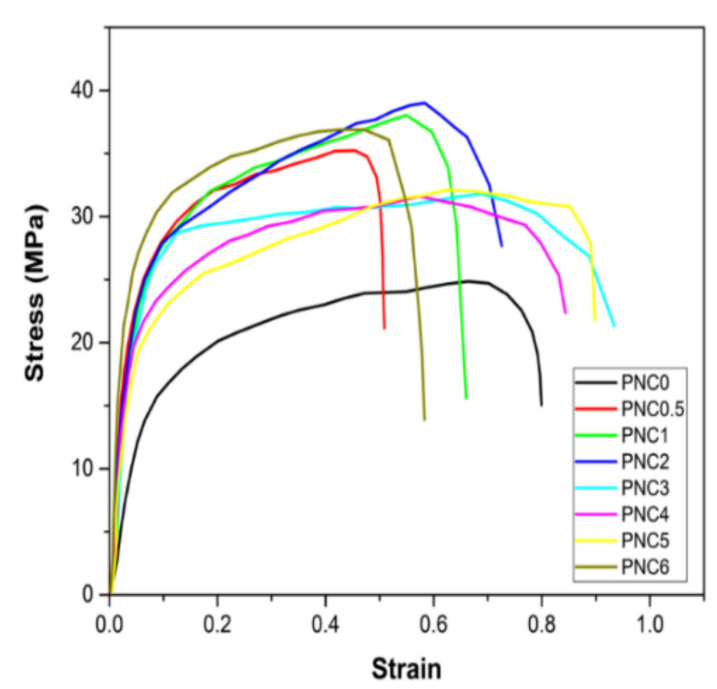

(a)

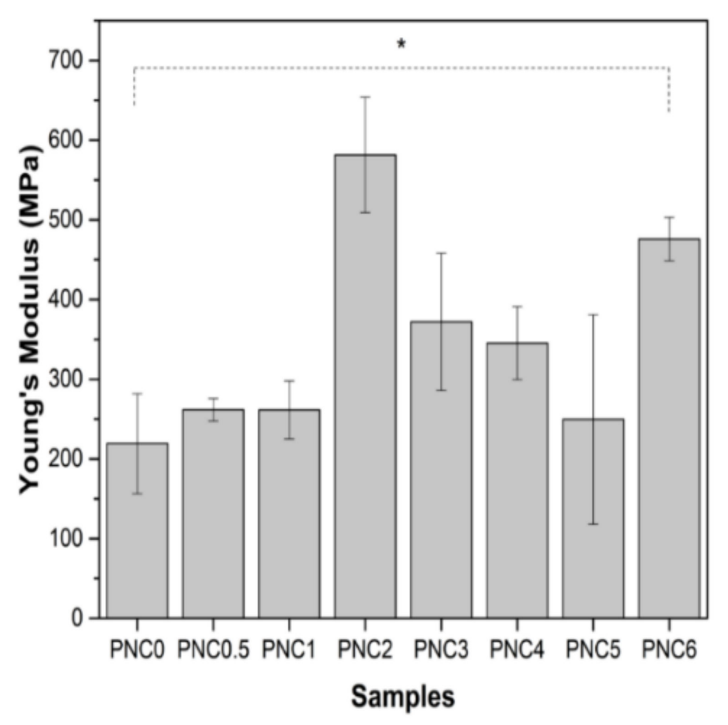

(c)

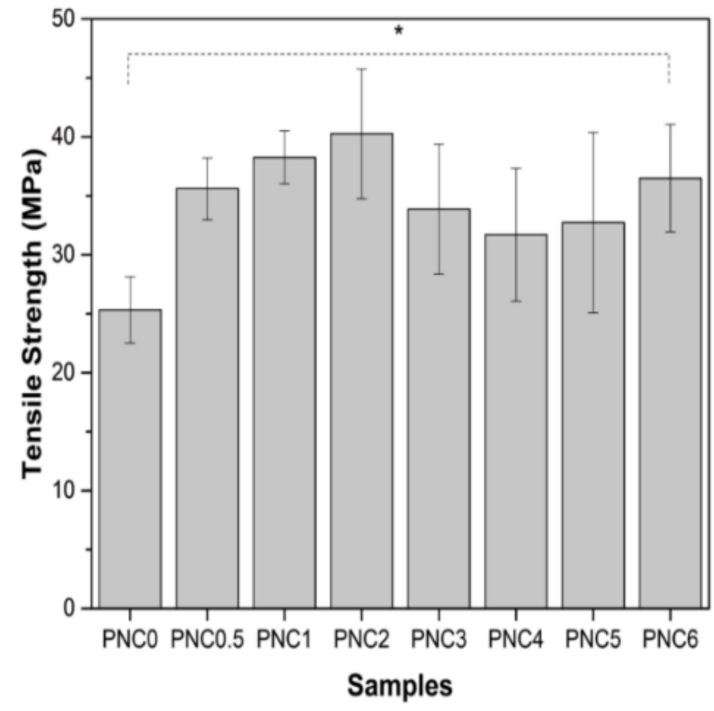

(b)

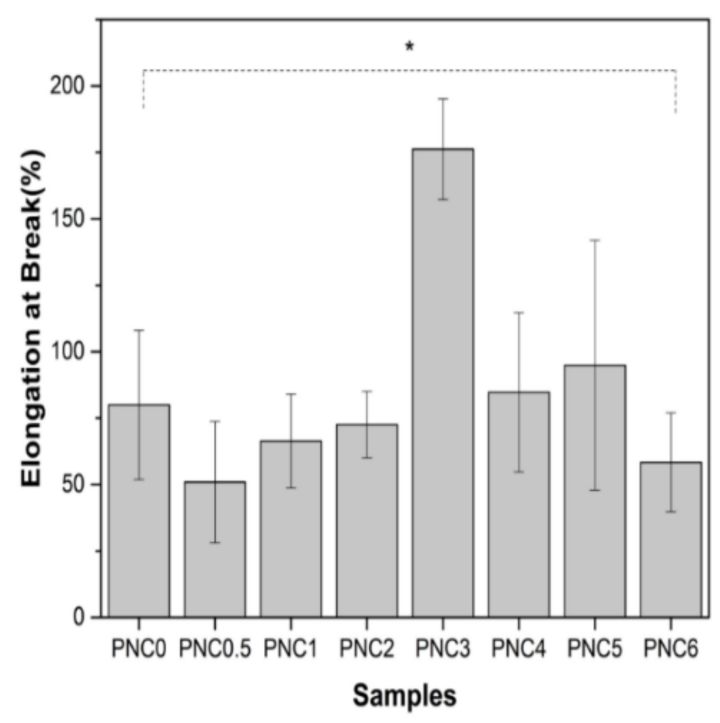

(d)

Figure 10. (a) The representative stress-strain curves of PVA-NCC nanocomposite films, (b) tensile strength, (c) Young's modulus, and (d) elongation at break of PVA-NCC nanocomposite films $(*: p<0.05)$.

\section{Conclusions}

In this study, NCC was successfully made from tea waste, and PVA nanocomposite was added, with NCC as a filler. Observations using SEM showed that tea decomposed due to the chemical treatment to obtain cellulose. Observations using TEM showed that cellulose was broken down into NCC due to acid hydrolysis. NCC was obtained with a 
diameter of $6.99 \pm 0.50 \mathrm{~nm}$. From XRD analysis, it was found that two peak regions were amorphous and had crystalline peaks, thus indicating that NCC had semi-crystalline properties and $63.8 \%$ crystallinity. The addition of NCC affected the characteristics of the PVA nanocomposite. SEM micrographs showed the distribution of NCC on the nanocomposite films. The FTIR results showed that the peak of the O-H functional group in PVA changed after NCC was added. The Raman spectroscopy results show that the ratio of $I_{(\mathrm{O}-\mathrm{H})} / I_{(\mathrm{C}-\mathrm{H})}$ is the crystallinity of the nanocomposite films after the addition of NCC, which follows the XRD results. The crystallinity increased, and subsequently, the maximum in the PNC2 composition decreased. The crystallinity affected the mechanical and thermal properties of the nanocomposite films. Mechanical properties have generally increased, as can be seen from the tensile strength and Young's modulus after adding the NCC. The thermal properties changed after NCC was added. The melting point and glass transition temperature decreased, the degradation temperature increased, and the enthalpy also changed. The addition of NCC decreased the swelling ratio and opacity value of the nanocomposite films. Thus, tea waste can be used as a raw material in the manufacture of NCC, and as a filler in nanocomposite films.

Author Contributions: Conceptualization, F.H. and Y.Y.; methodology, F.H. and Y.Y.; validation, F.H. and Y.Y.; formal analysis and investigation, F.H. and Y.Y.; writing_original draft preparation, F.H.; writing—review and editing, Y.Y.; supervision and project administration, Y.Y.; funding acquisition, Y.Y. All authors have read and agreed to the published version of the manuscript.

Funding: This research was funded by the Ministry of Education and Culture, Republic of Indonesia, through the PDUPT Grant (6536/UN1/DITLIT/DIT-LIT/PT/2021) and the Faculty of Mathematics and Natural Science, Universitas Gadjah Mada.

Institutional Review Board Statement: Not applicable.

Informed Consent Statement: Not applicable.

Data Availability Statement: Not applicable.

Acknowledgments: The authors are immensely grateful to the Ministry of Education and Culture, Republic of Indonesia, for the PDUPT Grant, and the Faculty of Mathematics and Natural Science, Universitas Gadjah Mada, for financially supporting this research. The authors acknowledge the facilities and the scientific and technical assistance of the Perseroan Terbatas Pagilaran, the Material Physics and Electronics Laboratory, and the staff of the Integrated Laboratory for Research and Testing at Universitas Gadjah Mada, Indonesia.

Conflicts of Interest: The authors declare no conflict of interest.

\section{References}

1. Takari, A.; Ghasemi, A.R.; Hamadanian, M.; Sarafrazi, M.; Najafidoust, A. Molecular dynamics simulation and thermo-mechanical characterization for optimization of three-phase epoxy/TiO2/SiO2 nano-composites. Polym. Test. 2021, 93, 106890. [CrossRef]

2. Yan, W.; Chen, Q.; Du, M.; Yang, K.M.; Cai, X.; Meng, X.; Wang, L. Highly Transparent Poly(vinyl alcohol)(PVA)/TiO2 Nanocomposite Films with Remarkable Photocatalytic Performance and Recyclability. J. Nanosci. Nanotechnol. 2018, 18, 5660-5667. [CrossRef] [PubMed]

3. Abdel-Hady, E.E.; Mohamed, H.F.M.; Abdel-Hamed, M.O.; Gomaa, M.M. Physical and electrochemical properties of PVA/TiO 2 nanocomposite membrane. Adv. Polym. Technol. 2018, 37, 3842-3853. [CrossRef]

4. Asad, M.; Saba, N.; Asiri, A.M.; Jawaid, M.; Indarti, E.; Wanrosli, W.D. Preparation and characterization of nanocomposite films from oil palm pulp nanocellulose/poly (Vinyl alcohol) by casting method. Carbohydr. Polym. 2018, 191, 103-111. [CrossRef] [PubMed]

5. Chiellini, E.; Cinelli, P.; Solaro, R.; Laus, M. Thermomechanical Behavior of Poly(vinyl alcohol) and Sugar Cane Bagasse Composites. J. Appl. Polym. Sci. 2004, 92, 426-432. [CrossRef]

6. Asgher, M.; Nasir, I.; Khalid, N.; Qamar, S.A. Development of biocomposites based on bacterial cellulose reinforced delignified rice husk-PVA plasticized with glycerol. J. Polym. Res. 2020, 27, 347. [CrossRef]

7. Kian, L.K.; Saba, N.; Jawaid, M.; Sultan, M.T.H. A review on processing techniques of bast fibers nanocellulose and its polylactic acid (PLA) nanocomposites. Int. J. Biol. Macromol. 2019, 121, 1314-1328. [CrossRef]

8. Spagnol, C.; Fragal, E.H.; Witt, M.A.; Follmann, H.D.M.; Silva, R.; Rubira, A.F. Mechanically improved polyvinyl alcoholcomposite films using modified cellulose nanowhiskers as nano-reinforcement. Carbohydr. Polym. 2018, 191, 25-34. [CrossRef] 
9. Zianor Azrina, Z.A.; Beg, M.D.H.; Rosli, M.Y.; Ramli, R.; Junadi, N.; Alam, A.K.M.M. Spherical nanocrystalline cellulose (NCC) from oil palm empty fruit bunch pulp via ultrasound assisted hydrolysis. Carbohydr. Polym. 2017, 162, 115-120. [CrossRef]

10. Wang, Y.; Wei, X.; Li, J.; Wang, F.; Wang, Q.; Zhang, Y.; Kong, L. Homogeneous isolation of nanocellulose from eucalyptus pulp by high pressure homogenization. Ind. Crops Prod. 2017, 104, 237-241. [CrossRef]

11. Niazi, M.B.K.; Jahan, Z.; Berg, S.S.; Gregersen, Ø.W. Mechanical, thermal and swelling properties of phosphorylated nanocellulose fibrils/PVA nanocomposite membranes. Carbohydr. Polym. 2017, 177, 258-268. [CrossRef]

12. Zielińska, D.; Szentner, K.; Waśkiewicz, A.; Borysiak, S. Production of nanocellulose by enzymatic treatment for application in polymer composites. Materials 2021, 14, 2124. [CrossRef] [PubMed]

13. Kassab, Z.; Abdellaoui, Y.; Salim, M.H.; Bouhfid, R.; Qaiss, A.E.K.; Achaby, M.E. Micro- and nano-celluloses derived from hemp stalks and their effect as polymer reinforcing materials. Carbohydr. Polym. 2020, 245, 116506. [CrossRef]

14. Abral, H.; Ariksa, J.; Mahardika, M.; Handayani, D.; Aminah, I.; Sandrawati, N.; Pratama, A.B.; Fajri, N.; Sapuan, S.; Ilyas, R. Transparent and antimicrobial cellulose film from ginger nanofiber. Food Hydrocoll. 2020, 98, 105266. [CrossRef]

15. Wu, H.; Nagarajan, S.; Shu, J.; Zhang, T.; Zhou, L.; Duan, Y.; Zhang, J. Green and facile surface modification of cellulose nanocrystal as the route to produce poly(lactic acid) nanocomposites with improved properties. Carbohydr. Polym. 2018, 197, 204-214. [CrossRef] [PubMed]

16. Rasheed, M.; Jawaid, M.; Parveez, B.; Zuriyati, A.; Khan, A. Morphological, chemical and thermal analysis of cellulose nanocrystals extracted from bamboo fibre. Int. J. Biol. Macromol. 2020, 160, 183-191. [CrossRef]

17. Kian, L.K.; Saba, N.; Jawaid, M.; Alothman, O.Y.; Fouad, H. Properties and characteristics of nanocrystalline cellulose isolated from olive fiber. Carbohydr. Polym. 2020, 241, 116423. [CrossRef]

18. Prado, K.S.; Spinacé, M.A.S. Isolation and characterization of cellulose nanocrystals from pineapple crown waste and their potential uses. Int. J. Biol. Macromol. 2019, 122, 410-416. [CrossRef]

19. Zhao, T.; Chen, Z.; Lin, X.; Ren, Z.; Li, B.; Zhang, Y. Preparation and characterization of microcrystalline cellulose (MCC) from tea waste. Carbohydr. Polym. 2018, 184, 164-170. [CrossRef]

20. Rahman, N.H.A.; Chieng, B.W.; Ibrahim, N.A.; Rahman, N.A. Extraction and characterization of cellulose nanocrystals from tea leaf waste fibers. Polymers 2017, 9, 588. [CrossRef]

21. Cano, A.I.; Cháfer, M.; Chiralt, A.; González-Martínez, C. Physical and microstructural properties of biodegradable films based on pea starch and PVA. J. Food Eng. 2015, 167, 59-64. [CrossRef]

22. Lee, H.; You, J.; Jin, H.J.; Kwak, H.W. Chemical and physical reinforcement behavior of dialdehyde nanocellulose in PVA composite film: A comparison of nanofiber and nanocrystal. Carbohydr. Polym. 2020, 232, 115771. [CrossRef] [PubMed]

23. Abral, H.; Ariksa, J.; Mahardika, M.; Handayani, D.; Aminah, I.; Sandrawati, N.; Sugiarti, E.; Muslimin, A.N.; Rosanti, S.D. Effect of heat treatment on thermal resistance, transparency and antimicrobial activity of sonicated ginger cellulose film. Carbohydr. Polym. 2020, 240, 116287. [CrossRef] [PubMed]

24. Sung, S.H.; Chang, Y.; Han, J. Development of polylactic acid nanocomposite films reinforced with cellulose nanocrystals derived from coffee silverskin. Carbohydr. Polym. 2017, 169, 495-503. [CrossRef] [PubMed]

25. Popescu, C.M.; Tibirna, C.M.; Raschip, I.E.; Popescu, M.C.; Ander, P.; Vasile, C. Bulk and surface characterization of unbleached and bleached softwood kraft pulp fibres. Cellul. Chem. Technol. 2008, 42, 525-547.

26. Januariyasa, I.K.; Ana, I.D.; Yusuf, Y. Nanofibrous poly(vinyl alcohol)/chitosan contained carbonated hydroxyapatite nanoparticles scaffold for bone tissue engineering. Mater. Sci. Eng. C 2020, 107, 110347. [CrossRef]

27. Benini, K.C.C.D.C.; Voorwald, H.J.C.; Cioffi, M.O.H.; Rezende, M.C.; Arantes, V. Preparation of nanocellulose from Imperata brasiliensis grass using Taguchi method. Carbohydr. Polym. 2018, 192, 337-346. [CrossRef] [PubMed]

28. Thiangtham, S.; Runt, J.; Manuspiya, H. Sulfonation of dialdehyde cellulose extracted from sugarcane bagasse for synergistically enhanced water solubility. Carbohydr. Polym. 2019, 208, 314-322. [CrossRef]

29. Basile, R.; Bergamonti, L.; Fernandez, F.; Graiff, C.; Haghighi, A.; Isca, C.; Lottici, P.P.; Pizzo, B.; Predieri, G. Bio-inspired consolidants derived from crystalline nanocellulose for decayed wood. Carbohydr. Polym. 2018, 202, 164-171. [CrossRef]

30. Galiwango, E.; Abdel Rahman, N.S.; Al-Marzouqi, A.H.; Abu-Omar, M.M.; Khaleel, A.A. Isolation and characterization of cellulose and $\alpha$-cellulose from date palm biomass waste. Heliyon 2019, 5, e02937. [CrossRef]

31. Sun, X.; Lu, C.; Liu, Y.; Zhang, W.; Zhang, X. Melt-processed poly(vinyl alcohol) composites filled with microcrystalline cellulose from waste cotton fabrics. Carbohydr. Polym. 2014, 101, 642-649. [CrossRef] [PubMed]

32. Ghorbel, N.; Kallel, A.; Boufi, S. Molecular dynamics of poly(vinyl alcohol)/cellulose nanofibrils nanocomposites highlighted by dielectric relaxation spectroscopy. Compos. Part A Appl. Sci. Manuf. 2019, 124, 105465. [CrossRef]

33. Mandal, A.; Chakrabarty, D. Characterization of nanocellulose reinforced semi-interpenetrating polymer network of poly(vinyl alcohol) \& polyacrylamide composite films. Carbohydr. Polym. 2015, 134, 240-250. [CrossRef] [PubMed]

34. Mandal, A.; Chakrabarty, D. Studies on the mechanical, thermal, morphological and barrier properties of nanocomposites based on poly(vinyl alcohol) and nanocellulose from sugarcane bagasse. J. Ind. Eng. Chem. 2014, 20, 462-473. [CrossRef]

35. Bahloul, A.; Kassab, Z.; El Bouchti, M.; Hannache, H.; Qaiss, A.E.K.; Oumam, M.; El Achaby, M. Micro- and nano-structures of cellulose from eggplant plant (Solanum melongena L) agricultural residue. Carbohydr. Polym. 2021, 253, 117311. [CrossRef]

36. Ventura-Cruz, S.; Flores-Alamo, N.; Tecante, A. Preparation of microcrystalline cellulose from residual Rose stems (Rosa spp.) by successive delignification with alkaline hydrogen peroxide. Int. J. Biol. Macromol. 2020, 155, 324-329. [CrossRef] 
37. Czaikoski, A.; da Cunha, R.L.; Menegalli, F.C. Rheological behavior of cellulose nanofibers from cassava peel obtained by combination of chemical and physical processes. Carbohydr. Polym. 2020, 248, 116744. [CrossRef]

38. Fortunati, E.; Puglia, D.; Luzi, F.; Santulli, C.; Kenny, J.M.; Torre, L. Binary PVA bio-nanocomposites containing cellulose nanocrystals extracted from different natural sources: Part I. Carbohydr. Polym. 2013, 97, 825-836. [CrossRef]

39. Wang, Z.; Qiao, X.; Sun, K. Rice straw cellulose nanofibrils reinforced poly(vinyl alcohol) composite films. Carbohydr. Polym. 2018, 197, 442-450. [CrossRef]

40. Alothman, O.Y.; Kia, L.; Saba, N.; Jawaid, M.; Khiari, R. Industrial Crops \& Products Cellulose nanocrystal extracted from date palm fibre: Morphological, structural and thermal properties. Ind. Crop. Prod. 2021, 159, 113075. [CrossRef]

41. Baruah, J.; Deka, R.C.; Kalita, E. Greener production of microcrystalline cellulose (MCC) from Saccharum spontaneum (Kans grass): Statistical optimization. Int. J. Biol. Macromol. 2020, 154, 672-682. [CrossRef] [PubMed]

42. Jahan, Z.; Niazi, M.B.K.; Gregersen, Ø.W. Mechanical, thermal and swelling properties of cellulose nanocrystals/PVA nanocomposites membranes. J. Ind. Eng. Chem. 2018, 57, 113-124. [CrossRef]

43. Abral, H.; Ariksa, J.; Mahardika, M.; Handayani, D.; Aminah, I.; Sandrawati, N.; Sapuan, S.; Ilyas, R. Highly transparent and antimicrobial PVA based bionanocomposites reinforced by ginger nanofiber. Polym. Test. 2020, 81, 106186. [CrossRef]

44. Popescu, M.C. Structure and sorption properties of CNC reinforced PVA films. Int. J. Biol. Macromol. 2017, 101, 783-790. [CrossRef] [PubMed]

45. George, J.; Ramana, K.V.; Bawa, A.S.; Siddaramaiah. Bacterial cellulose nanocrystals exhibiting high thermal stability and their polymer nanocomposites. Int. J. Biol. Macromol. 2011, 48, 50-57. [CrossRef]

46. Muralidharan, V.; Arokianathan, M.S.; Balaraman, M.; Palanivel, S. Tannery trimming waste based biodegradable bioplastic: Facile synthesis and characterization of properties. Polym. Test. 2020, 81, 106250. [CrossRef]

47. Oluwasina, O.O.; Olaleye, F.K.; Olusegun, S.J.; Oluwasina, O.O.; Mohallem, N.D.S. Influence of oxidized starch on physicomechanical, thermal properties, and atomic force micrographs of cassava starch bioplastic film. Int. J. Biol. Macromol. 2019, 135, 282-293. [CrossRef]

48. Tanpichai, S.; Oksman, K. Cross-linked nanocomposite hydrogels based on cellulose nanocrystals and PVA: Mechanical properties and creep recovery. Compos. Part A Appl. Sci. Manuf. 2016, 88, 226-233. [CrossRef]

49. Duan, J.; Jiang, J.; Li, J.; Liu, L.; Li, Y.; Guan, C. The preparation of a highly stretchable cellulose nanowhisker nanocomposite hydrogel. J. Nanomater. 2015, 2015, 963436. [CrossRef]

50. Cho, M.J.; Park, B.D. Tensile and thermal properties of nanocellulose-reinforced poly(vinyl alcohol) nanocomposites. J. Ind. Eng. Chem. 2011, 17, 36-40. [CrossRef]

51. Zanjanijam, A.R.; Bahrami, M.; Hajian, M. Poly (vinyl chloride)/Single Wall Carbon Nanotubes Composites: Investigation of Mechanical and Thermal Characteristics. J. Vinyl Addit. Technol. 2016, 22, 128-133. [CrossRef] 